\title{
Potencial de uso de declaração ambiental de produto para auxiliar em compras públicas verdes na construção civil
}

\author{
Potential use of environmental product declaration to \\ support green public procurement in civil construction
}

\section{Janaine Fernanda Gaelzer Timm Ana Carolina Badalotti Passuello}

\section{Resumo}

A

s compras públicas movimentam quantia considerável de recursos financeiros e têm o potencial de induzir práticas mais sustentáveis. Entretanto, permanecem barreiras para a sua efetiva implementação. O Programa das Nações Unidas para o Meio Ambiente aponta que um instrumento para auxiliar as compras públicas verdes (CPV) são fichas com informações ambientais, que facilitam a escolha e comparação entre alternativas e podem ser baseadas em técnicas de gestão ambiental como a avaliação do ciclo de vida (ACV) e/ou em declarações ambientais de produto (DAP). O objetivo deste artigo é explorar a abordagem do ciclo de vida nas CPV por meio da análise de DAP, e como suas informações podem integrar um instrumento para a construção civil. O trabalho conta com quatro etapas: análise do contexto; avaliação da estrutura das DAP; identificação das barreiras e oportunidades; investigação das DAP em CPV. Observa-se que o emprego das DAP nas fichas facilita o processo de elaboração e atualização delas, pois elas permitem a comparação entre produtos e a análise do equivalente ambiental, enquanto a ACV garante respaldo científico. Os resultados da revisão crítica mostram, ainda, que CPV são incipientes no contexto brasileiro, mas podem ser expandidas através do instrumento proposto no presente trabalho.

Palavras-chave: Compras públicas verdes. Declaração ambiental de produto. Fichas de desempenho ambiental. Construção civil.

1Janaine Fernanda Gaelzer Timm 'Universidade Federal do Rio Grande do

Porto Alegre - RS - Brasil

${ }^{2}$ Ana Carolina Badalotti Passuello 2Universidade Federal do Rio Grande do

Sul

Tramandaí - RS - Brasil

Recebido em 09/11/19

Aceito em 19/08/20

\begin{abstract}
Public Procurements move a considerable amount of financial resources and has the potential to induce more sustainable practices. However, there are barriers to the effective implementation of those practices. One of the tools recommended by the United Nations Environment Program (UNEP) to assist Green Public Procurement (GPP) are sheets with environmental information, as they help in the choice and comparison between alternatives and can be based on tools such as Life Cycle Assessment (LCA) and/or Environmental Product Declarations (EPD). The aim of this article is to explore the life cycle approach in GPP by analysing EPDs and how their information can feed the sheets for civil construction. This work was carried out in four steps: context analysis; evaluation of the structure of EPDs; identification of barriers and opportunities; investigation of EPDs in GPP. The study showed that the use of EPDs in the sheets helps the process of developing and updating them, as they allow comparisons to be made between products and the analysis of the environmental equivalent, while the LCA guarantees scientific support. The results of the critical review show the use GPP is still incipient in Brazil, but that it can be expanded through the tool proposed in this paper.
\end{abstract}

Keywords: Green public procurement. Environmental product declaration. Environmental performance sheets. Construction.

TIMM, J. F. G.; PASSUELLO, A. C. B. Potencial de uso de declaração ambiental de produto para auxiliar em compras 263 públicas verdes na construção civil. Ambiente Construído, Porto Alegre, v. 21, n. 2, p. 263-276, abr./jun. 2021. ISSN 1678-8621 Associação Nacional de Tecnologia do Ambiente Construído. http://dx.doi.org/10.1590/s1678-86212021000200525 


\section{Introdução}

A atual crise ambiental está atrelada a um desenvolvimento ecologicamente predatório, com meios de produção incoerentes com a capacidade regenerativa da Terra e diversos impactos associados. As compras públicas têm grande potencial transformador, incentivando a inovação do mercado por meio do enfrentamento dos desafios ambientais, e têm a capacidade de fomentar e conduzir o mercado em direção ao desenvolvimento sustentável, atuando, dessa forma, como um instrumento na concretização do direito fundamental ao meio ambiente sadio e ecologicamente equilibrado (CLEMENT et al., 2011; FINGER, 2013).

Compras públicas sustentáveis são definidas como as compras realizadas pelo Estado que incorporam requisitos que atendam ao tripé da sustentabilidade (esfera econômica, ambiental e social), contribuindo para que o Estado satisfaça as suas necessidades de bens e serviços, obtendo o melhor valor para o dinheiro despendido (VALENTE, 2011). Há também as compras públicas verdes (CPV), nas quais as aquisições públicas devem envolver outros aspectos além da funcionalidade e do custo, como os aspectos da dimensão ambiental. Com o intuito de estimular e auxiliar os países, o Programa das Nações Unidas para o Meio Ambiente (PNUMA) lança o Projeto Compras Públicas Sustentáveis e Rotulagem ambiental (em inglês Sustainable Public Procurement and Ecolabelling - SPPEL), cujo objetivo é fomentar o uso de duas ferramentas, compras públicas sustentáveis e rotulagem ambiental, que estimulam padrões de produção e consumo mais sustentáveis.

No Brasil, dados do Instituto Brasileiro de Geografia e Estatística (IBGE) indicam que as compras públicas movimentam aproximadamente $20 \%$ do Produto Interno Bruto (PIB) (INSTITUTO..., 2019). Devido ao seu grande poder de compra, a Administração Pública possui potencialmente uma grande influência sobre os seus fornecedores (ABREU, 2016) e são legitimadas pela Lei n. 12.349 (BRASIL, 2010) que inclui o termo "desenvolvimento nacional sustentável" no texto da Lei n. 8.666 (BRASIL, 1993) de Licitações Públicas. Mesmo com informações e incentivos internacionais, políticas e leis nacionais, as CPV no contexto brasileiro são pouco efetivas.

Devido à complexidade da incorporação da sustentabilidade no processo de compras, à diversidade de materiais e à diversidade de objetos (bens e serviços) a serem adquiridos, uma boa prática é o desenvolvimento de fichas técnicas com especificações padrão obtidas através da aplicação das seguintes ferramentas:

(a) aplicação da abordagem de ciclo de vida;

(b) aplicação da abordagem do custo total de posse;

(c) elaboração de especificações, contratos e demais documentos de aquisição;

(d) realização da consulta ao mercado;

(e) avaliação da conformidade (dos requisitos estabelecidos);

(f) monitoramento; e

(g) gestão dos contratos (ABREU, 2016).

O presente trabalho tem por objetivo revisar a abordagem de ciclo de vida nas CPV por meio da análise das declarações ambientais de produto (DAP), rótulos ambientais do Tipo III, e como suas informações podem alimentar as fichas de CPV do setor da construção civil.

\section{Compras Públicas Verdes (CPV)}

A mudança dos padrões de produção e consumo por meio de compras públicas apresenta diversas vantagens que permitem alcançar mudanças significativas nas esferas ambiental, social e econômica. Sua abordagem no contexto internacional não é recente, entretanto segue como um tópico atual e fundamental para a mitigação dos problemas ambientais, sociais e econômicos. Ao longo dos anos foram produzidos diferentes e variados materiais para difundir e simplificar a aplicação dessa prática. Entretanto, estudos apontam que algumas barreiras permanecem. Na Europa, por exemplo, são mencionados como barreiras:

(a) a falta de apoio político da gestão e de cooperação entre as autoridades;

(b) a percepção de maiores custos das CPV;

(c) a falta de capacitação e treinamentos para a aplicação de critérios ambientais;

264 Timm, J. F. G.; Passuello, A. C. B. 
(d) a ausência de ferramentas práticas e informações; e

(e) o reduzido número de critérios ambientais (UNITED..., 2012).

Nesse sentido, Alhola et al. (2018) apontam que o diálogo entre as partes é fundamental para o desenvolvimento de compras públicas com critérios ambientais e visando a economia circular. Cheng et al. (2018) indicam que a falta de rastreabilidade, priorização e avaliação dos critérios ambientais podem dificultar a implementação das CPV. Sönnichsen e Clement (2020) mencionam a ineficiência da estrutura pública, a ausência de regulamentos ambientais e o reduzido incentivo à inovação como dificuldades à implementação da sustentabilidade nos contratos públicos de aquisições. Liu et al. (2019) analisaram o contexto chinês e frisam que, para promover o desenvolvimento sustentável em países em desenvolvimento, é necessário engajar os tomadores de decisão do governo de modo a remover os obstáculos ideológicos e operacionais.

No contexto do Mercosul, as principais dificuldades encontradas são descritas a seguir:

(a) a aplicação de CPV demanda tempo que a equipe não dispõe, por estar envolvida em outras atividades;

(b) a percepção de que a temática é muito complexa e a dificuldade de compreensão;

(c) a descontinuidade das práticas nas trocas de gestão, evidenciando a necessidade de institucionalizar as políticas;

(d) os critérios e normas existentes, que priorizam a oferta de menor preço; e

(e) o conhecimento limitado sobre a temática e características ambientais (INSTITUTO...; UNITED..., 2008).

No contexto brasileiro, Teixeira (2013) captou, por meio de questionário em plataforma online, a percepção dos servidores públicos estaduais do estado de São Paulo que atuam em contratações públicas. A autora aponta que os motivos que mais dificultam a inserção de critérios de sustentabilidade nas licitações brasileiras são:

(a) a falta de capacitação dos responsáveis pelas compras;

(b) o desconhecimento de critérios de sustentabilidade;

(c) a falta de fornecedores e serviços sustentáveis;

(d) as dificuldade de comprovar e fiscalizar as exigências; e

(e) o preço elevado de itens sustentáveis.

Verifica-se que muitos itens apontados no âmbito internacional também estão presentes no contexto brasileiro.

Uma das maneiras de enfrentar tais barreiras é a existência de normativas específicas sobre contratações públicas que garantam a inclusão do desempenho ambiental. O Brasil conta com um arcabouço jurídico estruturado e com normativas e leis específicas para as compras públicas. As licitações e contratos públicos no Brasil são regidos pela Lei n. 8.666 (BRASIL, 1993). Em 2010, por meio da Lei número n. 12.349 (BRASIL, 2010a), o termo "desenvolvimento nacional sustentável" foi incluído no texto da Lei de Licitações. Dessa forma, todos os entes da Federação devem promover as licitações públicas verdes nos atos administrativos, o que nem sempre se verifica na prática.

A Lei n. 8.666 (BRASIL, 1993) apresenta alguns critérios que visam à economia de manutenção e operacionalização da edificação, a redução do consumo de energia e água, bem como a utilização de tecnologias e materiais que reduzam o impacto ambiental. Outras normativas que regulam as aquisições públicas são a Instrução Normativa n. 01 (MINISTÉRIO..., 2010), de 2010, e o decreto n. 7.746 (BRASIL, 2012). Os critérios apontados pela lei e pelas normativas são atribucionais e indiretos, isto é, apresentam características amplas e vagas que devem ser atendidas pelo projeto sem definir faixas ou valores mínimos de desempenho. Um exemplo disso é a menção ao emprego de materiais que reduzam o impacto ambiental sem fazer referência de como mensurar ou sobre qual ou quais impactos ambientais se trata. Fica evidente que a normativa cita as exigências ambientais que deveriam ser atendidas, mas em função do seu caráter restritivo e critérios amplos, há dificuldade para a sua implementação.

Diante do exposto acima, verifica-se que a estrutura de compras brasileiras menciona, porém não contempla de forma clara como devem ser abordados os impactos ambientais de produtos adquiridos através de compras públicas. Além disso, a prática atual analisa as opções considerando o equivalente funcional em 
curto prazo, isto é, comparando o desempenho sem considerar todo o ciclo de vida e as possíveis ações de manutenção e substituição. A escolha é realizada analisando o menor custo, que normalmente reflete apenas o preço inicial da aquisição e não o custo global de todo o seu ciclo de vida. Outra lacuna identificada é a não consideração do mesmo nível de desempenho ambiental do produto ou serviço, que é fruto da dificuldade em definir o que é similar ou equivalente na esfera ambiental e como mensurá-lo, considerando todo o ciclo de vida.

Devido à complexidade da incorporação da sustentabilidade no processo de compras, uma prática adotada em diferentes contextos - como o da União Europeia com o EU GPP CRITERIA (EUROPEAN..., 2018), o do Reino Unido com o The Green Guide to specification do BRE Group (BUILDING..., 2018) e da Colômbia com a Herramienta Análisis Costo Beneficios (Herramienta ACB) (MINISTERIO...; PROGRAMA...; CENTRO..., 2017) - é o desenvolvimento de instrumentos ou fichas com especificações padrão obtidas através de técnicas como a abordagem do ciclo de vida e a abordagem do custo total de posse (ABREU, 2016). Kanters (2020) menciona que a elaboração de documentos com informações ambientais, os passaportes ambientais, para o processo de tomada de decisão pode auxiliar significativamente na introdução da economia circular nas edificações. No contexto brasileiro, Dore (2015) explora a criação de banco de dados de materiais, baseado em DAP, com o objetivo de criar uma ferramenta de referência para os profissionais da construção civil a fim de facilitar o processo de tomada de decisão e o desenvolvimento de projetos mais sustentáveis.

Ainda no campo da produção científica sobre CPV, destaca-se o trabalho de Ruparathna e Hewage (2015), que identificou as práticas correntes em compras sustentáveis no setor de construção do Canadá. Os autores indicam que a maioria das publicações, entre 1864 e 2015, está centrada na identificação ou desenvolvimento de critérios ambientais. Um critério para avaliação das propostas que é destacado são as emissões de carbono em decorrência, principalmente, das agendas de ação climática.

Além disso, Cheng et al. (2018) realizaram uma revisão sistemática de literatura entre os anos 2000 e 2016 sobre CPV a fim de desenvolver um modelo conceitual das fases e identificar lacunas de pesquisa. Há destaque para um grande número de publicações nos últimos quatro anos de análise (2012 a 2016) com 41 artigos e uma predominância geográfica, com 57 artigos provenientes da Europa. Os autores salientam que o foco da literatura mudou ao longo do tempo, de conceitos mais gerais para tópicos mais concretos. Há poucos estudos que mencionam a $\mathrm{ACV}$, os rótulos ecológicos e a eficácia das $\mathrm{CPV}$, o que revela lacunas que merecem mais trabalho de pesquisa.

Historicamente, as autoridades públicas selecionam as propostas através do menor preço, independentemente da complexidade do projeto (KORYTÁROVÁ et al., 2015). Isso porque há pouco entendimento de como as instituições podem combinar com êxito as perspectivas econômica e ambiental ao adquirir bens e serviços (DE GIACOMO et al., 2019). Todavia, o mercado vem se adequando para incluir novos critérios e garantir uma combinação de qualidade, quantidade, risco, pontualidade e custo para as autoridades locais com base na vida útil de um produto, isto é, uma melhor relação entre custo e benefício (AHSAN; RAHMAN, 2017). Montalbán-Domingo et al. (2019) estabelecem que o sucesso de uma contratação está diretamente relacionado aos critérios estabelecidos para avaliar as propostas.

Para tanto, uma avaliação holística do ciclo de vida fornece às autoridades públicas melhores estratégias de monitoramento e análise das melhores práticas (TESTA et al., 2016). Sönnichsen e Clement (2020) apontam que uma combinação entre rótulos ecológicos (como as DAP), normas, ACV e custos podem auxiliar na definição de critérios que garantam transparência na avaliação do desempenho ambiental das CPV. BraulioGonzalo e Bovea (2020) também salientam que as CPV e os sistemas de certificação são instrumentos principais para reduzir os impactos ambientais de produtos e serviços do setor da construção civil e também criar soluções inovadoras e sustentáveis.

Portanto, verifica-se que a estrutura de compras brasileiras não foi construída em função da problemática ambiental, apesar da crescente conscientização quanto aos impactos e da urgência nas transformações dos padrões de produção e consumo, disseminados pelas políticas internacionais. Além disso, a prática atual analisa as opções considerando o menor custo, que normalmente reflete apenas o preço inicial da aquisição e não o custo global de todo o seu ciclo de vida. Outra lacuna identificada é a não consideração do desempenho ambiental do produto ou serviço, que é fruto da dificuldade em definir parâmetros para comparação. As CPV preenchem tal lacuna e evidências na literatura indicam que as fichas técnicas são uma das melhores opções para a implementação das aquisições verdes.

266 Timm, J. F. G.; Passuello, A. C. B. 


\section{Método}

O presente trabalho está organizado em quatro etapas, descritas de forma sucinta a seguir:

(a) análise do contexto internacional e brasileiro das DAP;

(b) análise da estrutura e informações das DAP;

(c) análise das barreiras e oportunidades das DAP; e

(d) verificação sobre o uso de DAP em CPV.

$\mathrm{Na}$ primeira etapa é realizada uma revisão bibliográfica exploratória sobre conceitos relativos às DAP e ao seu contexto, investigando como ela é elaborada e empregada em outros países e no contexto nacional.

$\mathrm{Na}$ segunda etapa é desenvolvida uma análise da estrutura das DAP e das regras de categoria de produtos (PCR) do setor da construção civil. Para analisar quais informações das DAP devem ser incorporadas nas fichas técnicas de CPV serão analisados os dados do EPD System, pois é o mais utilizado na Europa e o que vem sendo utilizado no contexto brasileiro (IBÁÑEZ-FORÉS et al., 2016).

$\mathrm{Na}$ terceira etapa ocorre a análise das barreiras e oportunidades para elaboração, implementação e uso da rotulagem tipo III, principalmente em países em desenvolvimento. Por fim, na última etapa realiza-se a verificação de quais informações das DAP têm relevância e potencial de integrar as fichas para auxiliar no processo de comparação de alternativas e tomada de decisão em CPV.

\section{Resultados e discussões}

No presente tópico serão apresentados os resultados obtidos por cada etapa, descritos nos subitens a seguir.

\section{Análise do contexto internacional e brasileiro das DAP}

Atualmente há 463 rótulos ambientais de tipo I, II e III, com origem em 199 países e de 25 setores (ECOLABEL..., 2020). Nesse repositório global não é possível realizar uma busca por tipo de rótulo, dessa forma não há como distinguir quantos desses são do tipo III, DAP. O alto número de programas de rotulagem enfatiza o fato de que há demanda por avaliações do desempenho ambiental (PASSER et al., 2015). O estudo desenvolvido por Hunsager, Bach e Breuer (2014) identificou:

(a) a existência de 27 programas de DAP;

(b) 556 regras de categorias de produtos $(\mathrm{RCP})$, sendo $66 \%$ delas oriundas de programas públicos; e

(c) a maioria das DAP, 13 delas aplicadas ao setor da construção civil.

Hoe e Pires (2017) ampliaram o estudo anterior e identificaram a existência de 39 programas, sendo 54\% de âmbito internacional e 44\% de setores em geral. Além disso, 56\% deles são da Europa, 28\% da América do Norte e o restante do resto do mundo. Os autores também elucidam que muitas DAP que inicialmente se restringiam aos produtos da construção civil se ampliaram e atingiram produtos voltados para o consumidor de maneira geral.

Na Europa há uma plataforma consolidada de avaliação do ciclo de vida (ACV) e uma forte tendência em tornar obrigatório o uso das DAP, que, aliado a um padrão normativo e legislativo consolidado, contribui para o desenvolvimento delas e a sua escolha como fonte principal para a construção de esquemas de avaliação ambiental (ARVIZU-PIÑA; BURGOS, 2017).

Quanto à produção científica, Dórea, Almeida Neto e Rodrigues (2018) realizaram uma revisão sistemática sobre rotulagem ambiental, no período de 2008 a 2017, e, dos 203 artigos selecionados, identificaram que os estudos sobre a rotulagem do tipo III têm o foco no setor da construção civil e materiais, sendo a maioria desses artigos advindos de países da Europa.

No Brasil, a criação do Programa de Rotulagem Tipo III foi instituída pela Portaria n. 100/2016, sob responsabilidade do Instituto Nacional de Metrologia, Qualidade e Tecnologia (Inmetro). O programa, que é voluntário, estabelece todas as diretrizes para a elaboração das DAP e das RCP, de modo que possa ser realizada por qualquer agente interessado. Ainda recente, ele está alinhado com os programas dos demais países, mas são necessários esforços para integrar essa política com outras ações já implementadas no país, como a Política Nacional de Resíduos Sólidos e as CPV, da mesma forma como ocorre em outros países (HOE; PIRES, 2017). 
No site do Inmetro ainda não há registros de DAP produzidas, entretanto a Fundação Vanzolini, representante do International EPD System, já registrou 12 DAP de empresas brasileiras, o que indica um crescimento potencial desse mercado no país, notadamente por conta do setor da construção civil (KISS et al., 2018). O setor também se destaca por conta do uso das DAP nas certificações AQUA-HQE e LEED versão 4, que propiciam incentivos tanto para os fabricantes criarem as DAP quanto para os projetistas implementarem em seus projetos (GELOWITZ; MCARTHUR, 2016).

\section{Análise da estrutura e informações das DAP}

As rotulagens ambientais são classificadas e devem ser formuladas a partir dos pressupostos da série de normas NBR 14020 (ABNT, 2002), que orientam sobre a precisão das informações, o uso de ferramentas científicas, a incorporação da abordagem do ciclo de vida e a transparência na comunicação dos resultados e do processo. De acordo com a norma, as rotulagens podem ser classificadas em três tipos:

(a) rotulagem I - selo verde;

(b) rotulagem II - autodeclaração ambiental; e

(c) rotulagem III - declaração ambiental de produto (DAP).

A rotulagem Tipo III, também de caráter voluntário, e mais conhecida por DAP, conta com uma estrutura padronizada e reconhecida internacionalmente para avaliar os impactos ambientais de materiais, componentes ou a avaliação completa do ciclo de vida do produto (SECHER; COLLIN; LINNET, 2018).

As DAP são definidas pela NBR 14025 (ABNT, 2015) como aquelas que fornecem dados ambientais quantificados para um produto empregando parâmetros pré-determinados $(\mathrm{RCP})$ e, onde forem relevantes, informações ambientais adicionais aos resultados da técnica de ACV. Os resultados do estudo de ACV devem ser verificados por terceira parte (isto é, a parte que verifica não deve ter relação nem com o operador de programa da rotulagem, nem com o cliente). Outra característica importante é que elas não impõem critérios sobre a preferência ambiental de um produto e nem estabelecem requisitos ambientais mínimos a serem cumpridos (BENVENISTE et al., 2011).

Para a elaboração das DAP é necessária a coleta de todas as entradas e saídas do processo produtivo em análise para a elaboração do inventário do ciclo de vida e seguir as demais instruções das RCP, que devem respeitar os pressupostos da EN 15804:2012+A1:2013 (EUROPEAN..., 2014). As DAP realizam uma avaliação ambiental e normalmente são específicas de um produto e de uma empresa (EPD..., 2019). O desempenho ambiental é informado através de sete categorias de impacto:
(a) potencial de aquecimento global (GWP-100);
(b) potencial de acidificação (AP);
(c) potencial de eutrofização (EP);
(d) potencial de oxidação fotoquímica (POCP);
(e) potencial de depleção da camada de ozônio (ODP);
(f) potencial de depleção de recursos abióticos de origem não fóssil (ADPN); e
(g) potencial de depleção de recursos abióticos de origem fóssil (ADPF).

Os sistemas de avaliação de edifícios, tais como AQUA-HQE e LEED versão 4, além de incorporarem recortes da técnica de ACV, também incorporam as DAP em suas avaliações. Ambas bonificam projetos que utilizam produtos que tenham DAP:

(a) no AQUA-HQE as DAP são valorizadas para os níveis mais elevados da categoria 2 e a pontuação é determinada pela parcela de declarações disponíveis para cada família de produtos; e

(b) na versão 4 do LEED, dois pontos são possíveis para projetos que possuem declarações ambientais que demonstram uma redução no impacto ambiental em relação à média da indústria (EPD..., 2018a).

A estrutura de uma DAP é composta de 5 grupos de informações (EPD..., 2018b):

(a) informações relacionadas ao programa (por exemplo RCP, validade da DAP);

(b) dados específicos do produto (tais como propriedades funcionais, declaração de conteúdo, entre outros);

(c) o desempenho ambiental (resultados da ACV e dados das fases do ciclo de vida); 
(d) informações ambientais adicionais (como, por exemplo, informações sobre o usuário e as fases de fim de vida); e

(e) declarações obrigatórias - sobre o processo, a empresa e a verificação de terceira parte.

Indicando que as DAP têm potencial para alimentar fichas técnicas de desempenho ambiental para CPV, é necessário avaliar quais informações serão utilizadas e como elas devem ser comunicadas.

\section{Análise de barreiras e oportunidades das DAP}

Para que as DAP sejam implementadas em países em desenvolvimento, como o Brasil, é preciso identificar as barreiras e oportunidades do processo e da ferramenta (ARVIZU-PIÑA; BURGOS, 2017). No contexto europeu, Ibáñez-Forés et al. (2016) identificam as potencialidades:

(a) capacidade de comunicação objetiva de informações;

(b) melhora da imagem corporativa;

(c) comunicação de grande volume de informações ambientais; e

(d) não exigência de cumprimento de nenhum critério.

Em outro estudo, Gelowitz e Mcarthur (2016), por meio de um questionário com projetistas que utilizaram as DAP no processo de certificação LEED versão 4, mapearam os principais benefícios do uso dos rótulos tipo III da perspectiva do projetista:

(a) a segurança da DAP apresentar resultados verificados por terceira parte;

(b) as DAP ajudaram a equipe a tomar decisões conscientes, adicionando profundidade às discussões de seleção; e

(c) o aumento do nível de conscientização e educação ambiental no escritório, pois havia maior disponibilidade de informações através de material transparente.

As principais barreiras incluem (IBÁÑEZ-FORÉS et al., 2016):

(a) questões financeiras como custos do processo e do estudo de ACV;

(b) aspectos técnicos e desconhecimento do processo;

(c) falta de cooperação internacional para padronização das RCP; e

(d) dificuldades de interpretação dos dados dos estudos de ACV e das DAP.

O estudo de Arvizu-Piña e Burgos (2017) destaca que os países em desenvolvimento enfrentam obstáculos adicionais como a ausência ou o atraso na implementação de regulamentos ambientais com abordagem do ciclo de vida e a dificuldade das indústrias, principalmente as pequenas e médias, de atender tais regulamentações.

Hoe e Pires (2017) apontam que as fraquezas do Sistema Brasileiro de DAP incluem o reduzido número de profissionais capacitados e com adequada experiência para elaboração do rótulo e a falta de infraestrutura para operacionalizar, o que pode levar a algumas ameaças, como o risco de não integração das RCP brasileiras com outras do mundo e a inexistência de organismos nacionais de terceira parte para a verificação dos dados. O enfrentamento de tais dificuldades está atrelado à existência de banco de dados de ACV e à consolidação do programa de DAP (HUNSAGER; BACH; BREUER, 2014).

Para que o Brasil acompanhe a tendência mundial do emprego da rotulagem do tipo III, é necessário que enfrente as barreiras apontadas e para isso é fundamental uma visão compartilhada de sustentabilidade entre governo e indústria; e uma sólida plataforma de conhecimento que apoie a ACV e sua comunicação (ARVIZU-PIÑA; BURGOS, 2017).

\section{Uso de DAP em Compras Públicas Verdes (CPV)}

A rotulagem ambiental do tipo III é considerada a mais adequada para relatar o desempenho ambiental de um produto de forma completa e detalhada, pois tem por premissa a obrigatoriedade de um painel com vários interessados para a construção das RCP, assim como a verificação por terceira parte independente (KISS et al., 2018). De acordo com Fernández-Viñé, Gómez-Navarro e Capuz-Rizo (2013), a DAP é um dos métodos menos onerosos para promover o desenvolvimento sustentável na Administração Pública. Elas não 
estabelecem padrões ou limites de desempenho ambiental, apenas métricas que possibilitam a comparação efetiva dos materiais que seguem a mesma RCP.

Apesar do elevado número de programas de DAP e de inúmeras RCP elaboradas, há um movimento de harmonização e internacionalização de ambas (IBÁÑEZ-FORÉS et al., 2016). Além disso, como as DAP são elaboradas pelas indústrias e verificadas pelas entidades acreditadas, elas têm o potencial de diminuir o nível de trabalho dos funcionários que elaboram as compras.

A maioria dos profissionais que elaboram as compras públicas, bem como os projetistas, não possui conhecimento aprofundado sobre impactos ambientais, portanto é importante que a comunicação seja completa, mas de maneira simples. Sönnichsen e Clement (2020) também complementam que as ferramentas de avaliação das propostas não devem ser complexas, pois elas podem se tornar um obstáculo à incorporação do desempenho ambiental nas compras públicas. Para que a comunicação seja efetiva, sugerese estabelecer meios de comparação, através do desenvolvimento de DAP setoriais dos principais produtos utilizados, para estabelecer valores para análise e estímulo de melhorias na cadeia produtiva. Com a definição de tais valores é possível realizar escolhas mais conscientes e baseadas em dados verificáveis. A definição de modelos e padrões para avaliar as propostas também é recomendado por Testa et al. (2016), pois a padronização da avaliação permite uma análise total do produto e uma visão geral do desempenho a ser avaliado.

No sistema proposto (Figura 1), são apresentados os dados do escopo do estudo de ACV, os impactos ambientais potenciais e seus respectivos fatores de caracterização definidos pela RCP de produtos da construção civil (EPD..., 2018c). Os dados de identificação permitem a classificação e armazenamento das fichas e estão alinhados com a estrutura mínima recomendada pela NBR ISO 14025 (ABNT, 2015). Nesse campo, constam dados referentes ao detalhamento do sistema construtivo, à validade da ficha, e ao estudo da $\mathrm{ACV}$ (fronteiras do sistema, unidade funcional, características de desempenho).

Figura 1 - Exemplo de comparação dos impactos ambientais de determinado sistema construtivo conforme instrumento de desempenho ambiental

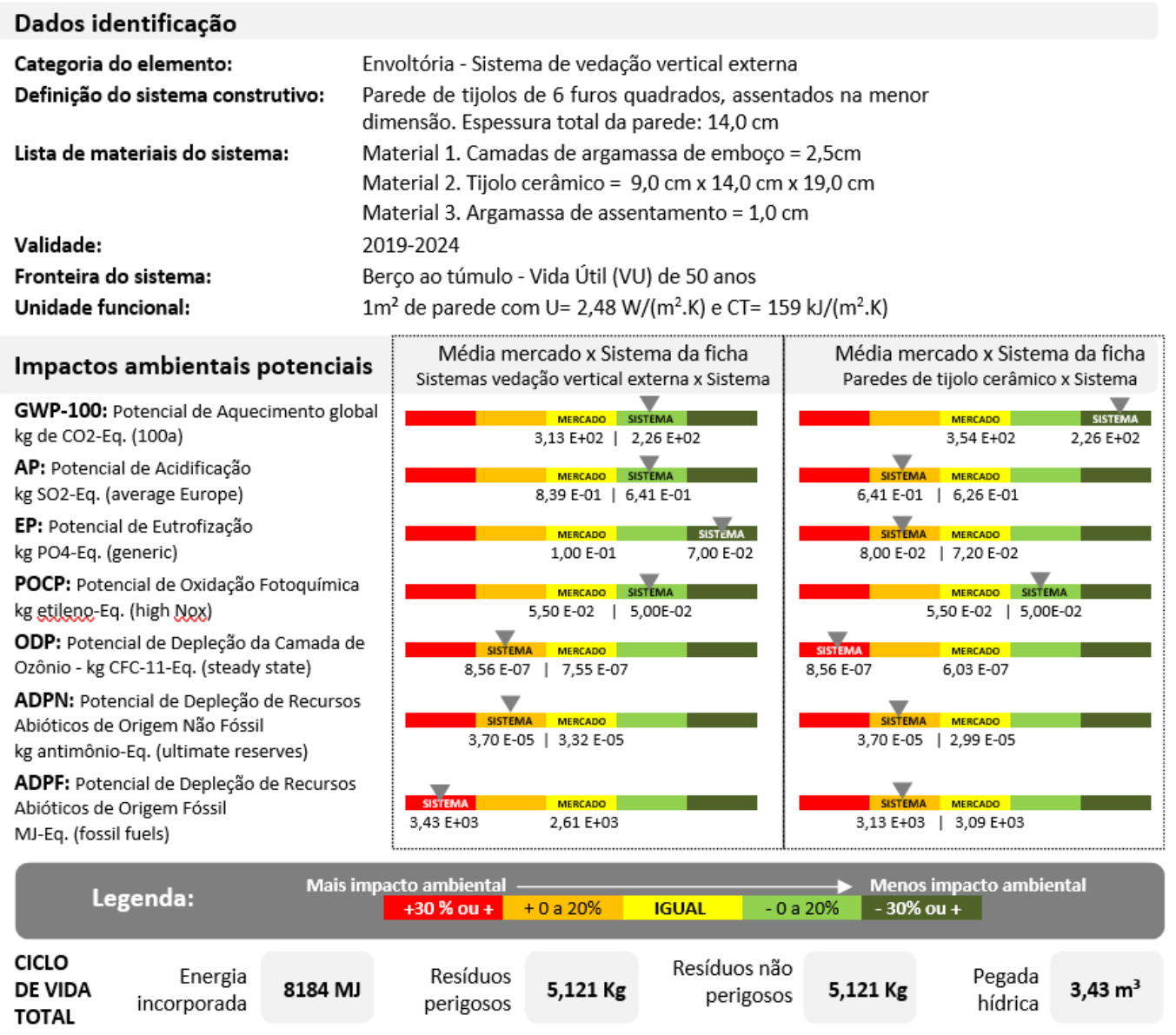


Os impactos ambientais são comunicados por meio de um sistema comparativo de barras entre as métricas médias do mercado definidas pelo Estado, por meio dos valores de DAP setoriais, bancos de inventários do ciclo de vida (ICV) e estudos de ACV.

A escala comparativa em barras coloridas estabelece uma relação entre os impactos ambientais do sistema em análise com os valores da métrica do mercado definida pela esfera pública. Para o lado direito, nos tons de verde, os impactos ambientais são menores que o valor de mercado. Logo, o desempenho ambiental é melhor que a média do mercado, visto que o sistema construtivo gera menos impactos ambientais. A cor amarela indica que o desempenho do sistema construtivo é igual ao valor de mercado. E os tons de laranja e vermelho indicam que o desempenho ambiental é pior quando comparado ao valor de mercado, pois os impactos ambientais são maiores. A meta da comparação é escolher sistemas construtivos cujo impacto ambiental seja classificado pelos tons de amarelo ou de verde quando comparados com os outros valores de mercado.

Na primeira comparação, é analisado o sistema construtivo da ficha com relação a outros sistemas da mesma categoria de elemento e considerando as demais opções disponíveis. No caso da ficha piloto, serão outros sistemas de vedação vertical externa como paredes de bloco de concreto, paredes de wood frame, de concreto moldada in loco entre outras.

O objetivo da primeira comparação, no retângulo da esquerda na Figura 1, é averiguar, entre as opções de sistemas construtivos, aquela mais adequada para determinado contexto e requisitos atrelados a ele. Na segunda comparação, no retângulo da direita, é analisado o sistema construtivo da ficha com relação a outros fornecedores da mesma tipologia, no piloto são as paredes de tijolos cerâmicos. O objetivo dessa comparação é realizar a melhor escolha entre as opções disponíveis dos fornecedores. Na escala comparativa são apresentados os dados da média de mercado e o do sistema construtivo da ficha, permitindo avaliar, de maneira rápida, se o valor do desempenho ambiental do sistema da ficha está melhor (com valores de impacto ambiental menores) ou pior (com impactos ambientais superiores) que o valor da métrica de mercado.

No Brasil, os critérios de sustentabilidade podem ser incorporados nos processos de compras públicas, desde que respeitem os princípios de isonomia, legalidade, impessoalidade, moralidade, publicidade, probidade administrativa, vinculação ao instrumento convocatório, julgamento objetivo e respeitada a competitividade do certame; como determina a Lei n. 8.666 (GOVERNOS...; MINISTÉRIO...; MINISTÉRIO..., 2013). A abordagem e inclusão da sustentabilidade em obras e serviços de engenharia podem ocorrer através da inserção de requisitos e indicadores nos aspectos técnicos constantes do projeto básico ou termo de referência, bem como pela observância da legislação e das normas vigentes no país e internacionais (CARVALHO; FERREIRA; VILLAC, 2016).

No caso do sistema proposto, a aplicação do desempenho ambiental seria através da incorporação no termo de referência do edital do desempenho ambiental a ser exigido, como, por exemplo, uma redução de $10 \%$ de Potencial de Aquecimento Global (em inglês Global Warming Potential - GWP) quando comparado com a métrica de mercado. As categorias de impacto empregadas no modelo proposto são abordadas por algumas certificações ambientais, como o LEED, que garante pontos extras para o edifício a ser certificado quando há comprovação da redução desses impactos ambientais.

Além disso, informações relativas ao consumo energético, produção de resíduos e consumo de recursos merecem ser destacadas e serem exigidas como requisitos nos processos de compras conforme indicado em políticas anteriores como a Lei de Eficiência Energética (BRASIL, 2001), Política Nacional de Mudança do Clima (BRASIL, 2009); e Política Nacional de Resíduos Sólidos (BRASIL, 2010).

Informações de atributos e suas quantidades (\%) também devem ser inseridas para que se incentive e se destaque ações como:

(a) substituição de substâncias ou materiais perigosos;

(b) uso de materiais reciclados;

(c) uso de fontes de energia renovável;

(d) uso eficiente de recursos energéticos; e

(e) uso eficiente de suprimentos.

Além disso, tais exigências podem fomentar o uso de certificações. 
As fichas, além de permitirem a incorporação da abordagem do ciclo de vida nas aquisições, também estabelecem métricas, com respaldo científico, para comparação e seguindo parâmetros definidos (RCP). Tal proposição está alinhada com as recomendações da UNEP (UNITED..., 2012), que indicam que as CPV devem ser baseadas no princípio de melhoria contínua e com dados da técnica de ACV, base para a elaboração das DAP. Além disso, Braulio-Gonzalo e Bovea (2020) reforçam que o setor da construção civil é um dos principais mercados para aumentar a competitividade e promover soluções sustentáveis e que nas CPV implementadas na Europa, muitos licitantes recebem pontos extras quando apresentam DAP ou estudos de ACV para os principais elementos do edifício, o mesmo ocorre em certificações ambientais como o LEED. Os critérios ambientais propostos são fatores fundamentais para a implementação bem sucedida das CPV e para isso precisam ser claros, relevantes, confiáveis e benéficos para a aquisição (SPARREVIK et al., 2018).

As DAP, sendo elaboradas e verificadas por outros agentes públicos e privados, contribuem para a gestão eficiente e reduzem a carga de trabalho em cada processo de licitação, desonerando os agentes compradores. Por ela também não estabelecer padrões de desempenho ou classificação, não há danos ao princípio da isonomia nas contratações públicas.

Por meio delas, o processo de comparação das opções torna-se mais ágil e fácil, pois todas elas contam com as mesmas informações e foram desenvolvidas com o mesmo rigor e regras. Tais características garantem maior confiabilidade ao comprador e ao projetista, que estão assegurados por meio de dados verificados e por uma ferramenta reconhecida pela esfera pública. Dessa forma, eles não se sentem ameaçados por punições jurídicas atreladas à improbidade administrativa e danos aos princípios de isonomia das contratações. $\mathrm{O}$ uso das fichas também fomentará avanços na agenda de ACV, pois, com as instituições internalizando a ferramenta, haverá incentivo na execução de estudos e a formação de bancos de dados regionalizados (APPUGLIESE; BETIOL; RAMOS, 2014).

\section{Considerações finais}

No setor da construção civil, uma das maiores dificuldades para a contratação de projetos sustentáveis é a ausência de métricas para avaliar os impactos ambientais dos produtos e das edificações. Com as fichas elaboradas a partir das DAP será possível avaliar os materiais e sistemas construtivos já nas fases iniciais. O passo inicial de desenvolver DAP setoriais dos principais elementos comprados e contratados pela esfera pública permitirá o estabelecimento de métricas que facilitarão as comparações. Na sequência, com outros dados individuais de fornecedores, será possível aprimorar as métricas.

No contexto brasileiro, com o início da exigência dos projetos públicos no formato BIM e da criação da plataforma BIM-BR (AGÊNCIA..., 2019), será possível exigir dos fornecedores a modelagem dos elementos com as informações ambientais atreladas a eles, garantindo maior celeridade ao processo e estimulando a consideração dos impactos ambientais nos processos de projeto. Considerar outros aspectos como o desempenho ambiental, além do menor preço, nas compras públicas induzirá o desenvolvimento sustentável e uma mudança no mercado, incentivando o consumidor a adotar melhores práticas.

A consolidação das CPV no contexto brasileiro requer o enfrentamento de desafios como o desenvolvimento do Programa Brasileiro de DAP, o crescimento do banco de inventários do ciclo de vida (ICV) nacional e a melhoria na conscientização dos funcionários e fornecedores quanto aos benefícios de considerar o ciclo de vida e o desempenho ambiental. Uma das formas de expandir seu uso é através das fichas de desempenho ambiental, elaboradas e atualizadas com informações das DAP. Além de permitirem a incorporação da abordagem do ciclo de vida nas aquisições, elas também estabelecem métricas, com respaldo científico (aplicando a ACV e seguindo a RCP), para comparação. As DAP, sendo elaboradas e verificadas por outros agentes públicos e privados, contribuem para uma gestão eficiente e reduzem a carga de trabalho em cada processo de licitação, desonerando os agentes compradores. Por ela não exigir padrões de desempenho ou classificação, também não há danos ao princípio da isonomia nas contratações públicas.

\section{Referências}

ABREU, J. A. A. K. P. Paper Brasil: considerações e recomendações para as Compras Públicas

Sustentáveis no Brasil: Projeto Sustainable Public Procurement and Ecolabelling. Rio de Janeiro: European Comission, 2016.

AGÊNCIA BRASILEIRA DE DESENVOLVIMENTO INDUSTRIAL. Biblioteca Nacional BIM. 2019.

Disponível em: https://plataformabimbr.abdi.com.br/bimBr/\#/objetos. Acesso em: 20 out. 2019. 
AHSAN, K.; RAHMAN, S. Green public procurement implementation challenges in Australian public health sector. Journal of Cleaner Production, v, 152, p. 181-197, 2017.

ALHOLA, K. et al. Exploiting the potential of public procurement. Journal of Industrial Ecology, v. 23, n. 1, p. 96-109, 2018.

APPUGLIESE, G. A.; BETIOL, L. S.; RAMOS, L. O pensamento do ciclo de vida como abordagem sistêmica para a tomada de decisão das compras públicas. In: CONGRESSO BRASILEIRO SOBRE GESTÃO PELO CICLO DE VIDA, 4., São Bernardo do Campo, 2014. Anais [...] São Bernardo do Campo: ABCV, 2014.

ARVIZU-PIÑA, V. A.; BURGOS, A. C. Promoting sustainability in Mexico's building sector via environmental product declarations. International Journal of Life Cycle Assessment, v. 22, n. 11, p. 1744-1759, 2017.

ASSOCIAÇÃO BRASILEIRA DE NORMAS TÉCNICAS. NBR ISO 14020: rótulos e declarações ambientais: princípios gerais. Rio de Janeiro, 2002.

ASSOCIAÇÃO BRASILEIRA DE NORMAS TÉCNICAS. NBR ISO 14025: rótulos e declarações ambientais: declarações ambientais de Tipo III: princípios e procedimentos. Rio de Janeiro, 2015.

BENVENISTE, G. et al. Análisis de ciclo de vida y reglas de categoría de producto en la construcción. El caso de las baldosas cerámicas. Informes de la Construcción, v. 63, n. 522, p. 71-81, 2011.

BRASIL, Decreto No 7.746, de 5 de junho de 2012. Disponível em: http://www.planalto.gov.br/ccivil_03/_ato2011-2014/2012/decreto/d7746.htm. Acesso em: 14 nov. 2020.

BRASIL. Lei $\mathbf{n}^{\circ} \mathbf{1 2 . 1 8 7}$, de 29 de dezembro de 2009 - Política Nacional de Mudança do Clima. Disponível em: http://www.planalto.gov.br/ccivil_03/_Ato2007-2010/2009/Lei/L12187.htm. Acesso em: 14 nov. 2020.

BRASIL. Lei no 10.295, de 17 de outubro de 2001 - Lei de eficiência energética. Disponível em: http://www.planalto.gov.br/ccivil_03/LEIS/LEIS_2001/L10295.htm. Acesso em: 14 nov. 2020.

BRASIL. Lei no 12.349, de 15 de dezembro de 2010. Disponível em: http://www.planalto.gov.br/ccivil_03/_Ato2007-2010/2010/Lei/L12349.htm. Acesso em: 14 nov. 2020.

BRASIL. Lei no 8.666, de 21 de junho de 1993 - Lei de licitações e contratos. Disponível em: http://www.planalto.gov.br/ccivil_03/leis/18666cons.htm. Acesso em: 14 nov. 2020.

BRAULIO-GONZALO, M.; BOVEA, M. D. Relationship between green public procurement criteria and sustainability assessment tools applied to office buildings. Environmental Impact Assessment Review, v. 81, 2020.

BUILDING RESEARCH ESTABLISHMENT. The Green Guide to Specification I BRE Group. 2018. Disponível em: https://www.bregroup.com/a-z/the-green-guide-to-specification/. Acesso em: 14 nov. 2020.

CARVALHO, F. G. de; FERREIRA, M. A. S. de O.; VILLAC, T. Guia nacional de licitações sustentáveis. Brasília, 2016.

CHENG, W. et al. Green Public Procurement, missing concepts and future trends: a critical review. Journal of Cleaner Production, v. 176, p. 770-784, 2018.

CLEMENT, S. et al. Incentivar a inovação e a eficiência energética através das compras: um guia prático para autoridades públicas. Friburgo, 2011.

DE GIACOMO, M. R. et al. Does Green Public Procurement lead to Life Cycle Costing (LCC) adoption? Journal of Purchasing and Supply Management, v. 25, n. 3, 2019.

DORE, B. F. L. Conceptualização de um banco de dados de materiais sustentáveis para a construção civil. São Paulo, 2015. 140 f. Trabalho de Conclusão de Curso (Engenharia de Produção) - Escola Politécnica, Universidade de São Paulo, São Paulo, 2015.

DÓREA, R. J. dos S.; ALMEIDA NETO, J. A. de A.; RODRIGUES, L. B. Revisão sistemática da rotulagem ambiental da última década. In: CONGRESSO BRASILEIRO SOBRE GESTÃO DO CICLO DE VIDA, 6., Brasília, 2018. Anais [....] Brasília: ABCV, 2018.

ECOLABEL INDEX. Who's deciding what's green? Disponível em: http://www.ecolabelindex.com/. Acesso em: 21 maio 2020. 
EPD SYSTEM. Comunicação com declarações ambientais de produto. 2018b. Disponível em: https:/www.environdec.com/contentassets/4b9089c8351649608e026cfb899ef04a/communicatingepd_portuguese.pdf. Acesso em: 21 maio 2020.

EPD SYSTEM. Creating EPDs. Disponível em: https://www.environdec.com/Creating-EPDs/. Acesso em: 21 out. 2019.

EPD SYSTEM. Declarações ambientais de produtos. 2018a. Disponível em: https://www.environdec.com/. Acesso em: 21 maio 2020.

EPD SYSTEM. Product Category Rules (PCR): construction products and construction services - 2012:01 - Version 2.3. 2018c. Disponível em: https:/www.environdec.com/PCR/Detail/?Pcr=8098. Acesso em: 21 out. 2019.

EUROPEAN COMMISSION. GPP Criteria - Environment - European Commission- Background and approach. 2018. Disponível em: http://ec.europa.eu/environment/gpp/gpp_criteria_en.htm. Acesso em: 21 out. 2019.

EUROPEAN COMMITTEE FOR STANDARDIZATION. EN 15804:2012+A1:2013: sustainability of construction works: environmental product declarations: core rules for the product category of construction products. Luxemburg: Publications Office of the European Union, 2014.

FERNÁNDEZ-VIÑÉ, M. B.; GÓMEZ-NAVARRO, T.; CAPUZ-RIZO, S. F. Assessment of the public administration tools for the improvement of the eco-efficiency of Small and Medium Sized Enterprises. Journal of Cleaner Production, v. 47, p. 265-273, 2013.

FINGER, A. C. Licitações sustentáveis como instrumento de política pública na concretização do direito fundamental ao meio ambiente sadio e ecologicamente equilibrado. A\&C - Revista de Direito

Administrativo \& Constitucional, v. 51, p. 121-153, 2013.

GELOWITZ, M. D. C.; MCARTHUR, J. J. Investigating the effect of environmental product declaration adoption in LEED $^{\circledR}$ on the construction industry: a case study. Procedia Engineering, v. 145, p. 58-65, 2016.

HOE, V. M. H.; PIRES, A. C. A construção do sistema brasileiro de declaração ambiental de produto. Sustentabilidade em Debate, v. 8, n. 2, p. 44-59, 2017.

HUNSAGER, E. A.; BACH, M.; BREUER, L. An institutional analysis of EPD programs and a global PCR registry. International Journal Life Cycle Assessment, v. 19, n. 4, p. 786-795, 2014.

IBÁÑEZ-FORÉS, V. et al. Environmental product declarations: exploring their evolution and the factors affecting their demand in Europe. Journal of Cleaner Production, v. 116, p. 157-169, 2016.

GOVERNOS LOCAIS PELA SUSTENTABILIDADE; MINISTÉRIO DO PLANEJAMENTO ORÇAMENTO E GESTÃO; MINISTÉRIO DO DESENVOLVIMENTO, INDÚSTRIA E COMÉRCIO. Compras sustentáveis pela inovação e por uma economia verde e inclusiva: relatório de diretrizes aos planos de gestão de logística sustentável (IN MP/SLTI no 10/2012). Brasília, 2013.

INSTITUTO ARGENTINO PARA EL DESARROLLO SUSTENTABLE; UNITED NATIONS PROGRAMME. Compras Públicas Sustentables en el MERCOSUR: lineamientos para la elaboración de políticas. Buenos Aires, 2008.

INSTITUTO BRASILEIRO DE GEOGRAFIA E ESTATÍSTICA. Participação da despesa de consumo das administrações públicas em relação ao produto interno bruto. Disponível em:

https://seriesestatisticas.ibge.gov.br/series.aspx?no=12\&op=0\&vcodigo=SCN34\&t=participacao-+despesaconsumo-administracoes-publicas-brem. Acesso em: 26 out. 2019.

KANTERS, J. Circular building design: an analysis of barriers and drivers for a circular building sector. Buildings, v. 10, n. 4, 2020.

KISS, B. et al. Panorama de selos de sustentabilidade que demandam rotulagem tipo III no Brasil. In: CONGRESSO BRASILEIRO SOBRE GESTÃO DO CICLO DE VIDA, 6., Brasília, 2018. Anais [...] Brasília: ABCV, 2018.

KORYTÁROVÁ, J. et al. Exploring the contractors' qualification process in public works contracts. Procedia Engineering, v. 123, p. 276-283, 2015. 
LIU, J. et al. Enhancing green public procurement practices in local governments: Chinese evidence based on a new research framework. Journal of Cleaner Production, v. 211, p. 842-854, 2019.

MINISTERIO DE AMBIENTE Y DESARROLLO SOSTENIBLE; PROGRAMA DE LAS NACIONES UNIDAS PARA EL MEDIO AMBIENTE; CENTRO NACIONAL DE PRODUCCIÓN MÁS LIMPIA Y TECNOLOGÍAS AMBIENTALES. Estimulación de la oferta y la demanda de productos sostenibles a través de la contratación pública sostenible y eco-etiquetado (SPPEL): especificaciones técnicas de la herramienta análisis costo beneficios. 2017. Disponível em: http://www.ncbi.nlm.nih.gov/pubmed/9531422. Acesso em: 21 out. 2020.

MINISTÉRIO DO PLANEJAMENTO, ORÇAMENTO E GESTÃO. Instrução normativa nº 01 , de 19 de janeiro de 2010. Brasília, 2010.

MONTALBÁN-DOMINGO, L. et al. Social sustainability in delivery and procurement of public construction contracts. Journal of Management in Engineering, v. 35, n. 2, p. 1-11, 2019.

PASSER, A. et al. Environmental product declarations entering the building sector: critical reflections based on 5 to 10 years experience in different European countries. International Journal of Life Cycle Assessment, v. 20, n. 9, p. 1199-1212, 2015.

RUPARATHNA, R.; HEWAGE, K. Sustainable procurement in the Canadian construction industry: current practices, drivers and opportunities. Journal of Cleaner Production, v. 109, p. 305-314, 2015.

SECHER, A. Q.; COLLIN, C.; LINNET, A. Construction product declarations and sustainable development goals for small and medium construction enterprises. Procedia CIRP, v. 69, p. 54-58, May 2018.

SÖNNICHSEN, S. D.; CLEMENT, J. Review of green and sustainable public procurement: towards circular public procurement. Journal of Cleaner Production, v. 245, 2020.

SPARREVIK, M. et al. Green public procurement: a case study of an innovative building project in Norway. Journal of Cleaner Production, v. 188, p. 879-887, 2018.

TEIXEIRA, M. F. F. B. Desafios e oportunidades para a inserção do tripé da sustentabilidade nas contratações públicas : um estudo dos casos do Governo Federal Brasileiro e do Governo do Estado de São Paulo. Brasília, 2013. 312 f. Dissertação (Mestrado em Desenvolvimento Sustentável) - Universidade de Brasília, Brasília, 2013.

TESTA, F. et al. Examining green public procurement using content analysis: existing difficulties for procurers and useful recommendations. Environment Development and Sustainability, v. 18, p. 197-219. 2016.

UNITED NATIONS ENVIRONMENT PROGRAMME. Sustainable public procurement implementation guidelines: introducing UNEP's Approach. França, 2012.

VALENTE, M. A. L. Marco legal das licitações e compras sustentáveis na administração pública. 2011. Disponível em: http://bd.camara.gov.br/bd/handle/bdcamara/5704. Acesso em: 21 maio 2020.

\section{Agradecimentos}

Os autores agradecem às instituições que apoiam os pesquisadores envolvidos neste estudo: CNPq (no. 306045/2018-4; 429264/2018-6), CAPES (no. 429264/2018-6), FAPERGS e UFRGS/FEEng. 
Janaine Fernanda Gaelzer Timm

Programa de Pós-Graduação em Engenharia Civil - Construção e Infraestrutura | Universidade Federal do Rio Grande do Sul | Av. Osvaldo Aranha, 99, Centro Histórico | Porto Alegre - RS - Brasil | CEP 90035-190 | Tel.: (51) 3308-3518 | E-mail: janainetimm@hotmail.com

\title{
Ana Carolina Badalotti Passuello
}

Programa de Pós-Graduação em Engenharia Civil - Construção e Infraestrutura | Departamento Interdisciplinar | Universidade Federal do Rio Grande do Sul | Campus Litoral Norte, Prédio 61508, RS 030, KM 91 | Tramandaí - RS - Brasil | CEP 95590-000 | Tel.: (51) 3308-1332 | E-mail: ana.passuello@ufrgs.br

\author{
Ambiente Construído \\ Revista da Associação Nacional de Tecnologia do Ambiente Construído \\ Av. Osvaldo Aranha, $99-3^{\circ}$ andar, Centro \\ Porto Alegre - RS - Brasil$$
\text { CEP } 90035-190
$$ \\ Telefone: +55 (51) 3308-4084 \\ Fax: +55 (51) 3308-4054 \\ www.seer.ufrgs.br/ambienteconstruido \\ E-mail: ambienteconstruido@ufrgs.br
}

This is an open-access article distributed under the terms of the Creative Commons Attribution License.

276 Timm, J. F. G.; Passuello, A. C. B. 